\title{
DESENVOLVIMENTO DE UM EQUIPAMENTO PARA A PRODUÇÃO DE CERA ALVEOLADA
}

\author{
C. ZIEGLER, T. SINIGAGLIA* e A. MICHELS
Faculdade de Horizontina
ts001117@fahor.com.br ${ }^{*}$ \\ Artigo submetido em dezembro/2015 e aceito em fevereiro/2016 \\ DOI: 10.15628/holos.2016.3742
}

\section{RESUMO}

A cera alveolada é muito importante para a produção de mel, pelo fato de que minimiza o trabalho e o gasto de energia das abelhas na produção dos favos. O problema em questão é que existem poucos equipamentos que produzem cera alveolada, limitando o processo. Sendo assim, é de grande importância o desenvolvimento de equipamentos destinados a produção de cera alveolada em larga escala, possibilitando novas oportunidades para os apicultores. Desse modo, o objetivo principal do trabalho é desenvolver um equipamento capaz de transformar cera bruta em cera alveolada, levando em conta, as características e métodos existentes para alveolar a cera de abelha, encontradas nas bibliografias existentes, e a definição desses processos, seguidos da elaboração de desenhos com auxílio computacional. Para alcançar os objetivos expostos no trabalho foi realizada pesquisa bibliográfica, para verificar as características físicas da cera de abelha, e a definição dos processos necessários para transformar cera bruta em cera alveolada. No presente trabalho também são apresentados detalhadamente todos os sistemas que compõe o equipamento e o equipamento completo. Como conclusão destaca-se que o objetivo principal foi atingido, pois foi possível o desenvolvimento de um equipamento capaz de produzir cera alveolada de forma contínua.

PALAVRAS-CHAVE: Cera Alveolada, Equipamentos, Cera Bruta.

\section{DEVELOPMENT OF AN EQUIPMENT FOR THE PRODUCTION OF WAX HONEYCOMB}

\begin{abstract}
The beeswax is very important for the production of honey by the fact the works and minimizes the energy expenditure of the bees in the production of honeycombs. The issue at hand is that there are few facilities that produce beeswax, limiting the process. Therefore, it is of great importance to develop equipment for the production of beeswax on a large scale, providing new opportunities for beekeepers. Thus, the main objective is to develop a device capable of transforming raw wax in beeswax. To achieve the objectives set forth
\end{abstract}

in the work literature search was performed to verify the physical characteristics of beeswax, and the definition of the processes required to transform raw wax in beeswax. The following results are also presented in the details: wax lamination system, system modeling wax, wax cutting system, support structure, drive mechanisms and presentation of full equipment In conclusion we emphasize that the main objective was a achieved, and it was possible to develop a device.

KEYWORDS: Wax Honeycomb, Equipment, Raw Wax.

\section{LISTA DE SÍMBOLOS}

$\mathrm{Q}:$ quantidade de calor $(\mathrm{J})$;

m: massa (kg);

c: calor específico $\left(\mathrm{J} / \mathrm{kg} .{ }^{\circ} \mathrm{C}\right)$;

Fc: força de corte $(\mathrm{N})$;

Kc: pressão específica de corte $\left(\mathrm{N} / \mathrm{m}^{2}\right)$;
A: seção de usinagem $\left(\mathrm{m}^{2}\right)$;

b: comprimento do gume ativo (m);

$\mathrm{h}$ : espessura do cavaco $(\mathrm{m})$;

Pr: perímetro do cilindro $(\mathrm{m})$;

Alc: área lateral do cilindro $(\mathrm{m})$;

Vcl: Volume de cera laminada $\left(\mathrm{m}^{3}\right)$;
Mt: momento torsor (N.m);

$r$ : raio do cilindro $(\mathrm{m})$;

$P$ : potência (w);

$\mathrm{W}$ : velocidade angular (rads/s);

$\mathrm{M}$ : vazão mássica (g/min);

$\Delta$ t: variação de temperatura $\left({ }^{\circ} \mathrm{C}\right)$. 


\section{INTRODUÇÃO}

A cera é utilizada pelas abelhas na construção dos favos para o armazenamento de alimento. Para facilitar o trabalho da abelha na produção de cera, o apicultor utiliza a cera alveolada, que orienta as abelhas na construção do favo, ajudando-as na confecção do tamanho da célula. Este tipo de cera é importante para a colmeia, portanto, existe a necessidade de um equipamento simples e com baixo custo para produzir cera alveolada.

No mercado existem poucos modelos de equipamentos disponíveis para a produção desse tipo de cera. A maioria desses equipamentos são rústicos e de baixa eficiência, tornando difícil a produção da cera alveolada em uma escala maior de cinquenta quilogramas por dia. A baixa eficiência é relacionado ao fato que a maioria dos equipamentos são manuais, devido a isso a produção é limitada a uma pequena quantidade de cera laminada por dia. O problema a ser resolvido é: Como desenvolver um equipamento capaz de transformar cera bruta em cera alveolada, mantendo a uniformidade no produto final?

Esta pesquisa tem como objetivo geral desenvolver um equipamento capaz de transformar cera bruta em cera alveolada. Como objetivos específicos tem-se como meta definir os processos necessários para transformar cera bruta em cera alveolada e elaborar os desenhos do equipamento com auxilio do software Solidworks.

É de grande importância o desenvolvimento deste trabalho em virtude de que existem poucos equipamentos no mercado destinados a produção de cera alveolada. Normalmente os equipamentos disponíveis são manuais e com métodos artesanais, lentos e de baixa qualidade, tornando o produto muitas vezes com baixa uniformidade. Esses equipamentos necessitam do trabalho constante do apicultor, pois ele precisa derreter a cera e colocá-la em moldes, então deve esperar que a mesma esfrie, após desprendê-la do molde, precisa passar a cera em cilindros manuais para moldar os alvéolos, e o corte da cera alveolada é realizado normalmente com estiletes ou facas.

\section{REVISÃO DE LITERATURA}

\subsection{Apicultura}

A apicultura é o nome dado à criação racional de abelhas Apis melífera para fins de lazer e/ou comercial. Neste sistema as abelhas são criadas para a produção de mel, pólen, geleia real, apitoxina, própolis e cera (NUNES et al. 2012, p.7).

De acordo com Corrêa (2003) a apicultura é capaz de causar impactos positivos, sociais e econômicos, e favorece a manutenção e preservação dos ecossistemas. Sua cadeia produtiva propicia a geração de inúmeros postos de trabalho, empregos e fluxo de renda, principalmente para a agricultura familiar.

Devido à apicultura ser uma atividade importante, existe a necessidade de profissionalização e atualização das técnicas utilizadas. Além disso, com o crescimento da apicultura surgem novas oportunidades de diversificação de produtos, possibilitando novos ganhos e a manutenção da produtividade (NUNES et al. 2012, p.7). 
Existem vários tipos de colmeias, as mais importantes são a Americana (ou Langstroth), a Schenk, a Curtinaz e a Schirmer. Segundo Araújo (1983) alguns tipos caíram em desuso, e o padrão de colmeia adotado no mundo inteiro é a do tipo Americana. A figura 1 apresenta uma colmeia americana com suas partes.

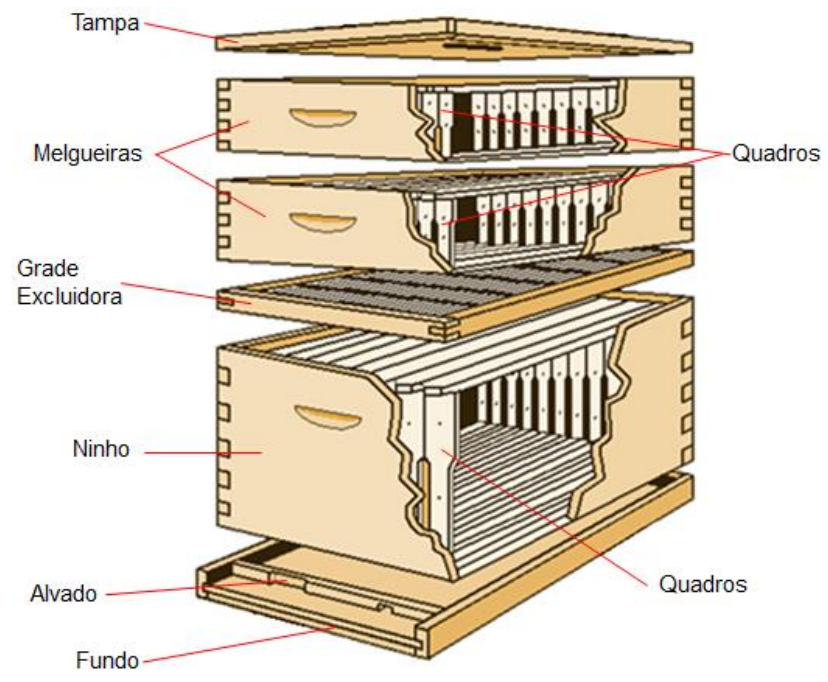

Figura 1: Colmeia americana e suas partes. Fonte: Adaptado de Lostlakegardens (2013).

Cada componente da colmeia apresentado na figura 1 tem uma função, Araújo (1983) apresenta essas funções: 1) Tampa: protege o interior da colmeia contra o frio e a entrada de elementos prejudiciais. 2) Melgueiras: parte com quadros onde é depositado o mel. 3) Quadros: são armações onde as abelhas vão construir os favos de cera com alvéolos hexagonais, para criar filhotes e deposição de mel, água e pólen. 4) Grade Excluidora: é colocada para evitar que a rainha acesse as melgueiras destinadas à produção de mel. 5) Ninho: parte com quadros destinados a depósito de mel, pólen ou crias. 6) Alvado: a porta da colmeia, por onde ocorre a entrada e saída das abelhas. 7) Fundo: parte inferior da colmeia.

\subsection{Cera de abelha}

Para Huertas, Garay e Sá (2009) a cera é um elemento vital para o enxame, ao qual sem ela não existiria a colmeia. As abelhas sempre empregam a cera nos trabalhos mais delicados, e nunca a desperdiçam em obras secundárias, pois para as abelhas a cera representa o principal material na arquitetura de suas colmeias.

De acordo com Nunes et al. (2012) a cera é utilizada pelas abelhas na construção dos favos para armazenamento de seu próprio alimento e para o desenvolvimento das crias, e ainda é utilizada na composição da própolis.

Segundo Costa e Oliveira (2005) a cera apresenta uma densidade de 0,960 a 0,972 g/ $\mathrm{cm}^{3}$, com ponto de fusão variando de $60^{\circ} \mathrm{C}$ a $65^{\circ} \mathrm{C}$. O calor específico da cera de abelha é de 0,70 $\mathrm{kcal} / \mathrm{kg}$. ํC (CASAFERREIRA, 2014). A pressão específica de corte para cera de abelha é $526,7 \mathrm{kPa}$ (HOSSAIN et al. 2009).

Sua composição química apresenta: 70 a $72 \%$ de ésteres; 14 a $15 \%$ de ácidos céricos livres; $12 \%$ de hidrocarbonetos predominantemente saturados; $1 \%$ de álcoois. A cera possui características físicas estáveis, ela é quebradiça quando fria, e acima de $30{ }^{\circ} \mathrm{C}$ torna-se plástica, podendo ser moldada. 


\subsection{Alveolação}

De acordo com Barros, Nunes e Costa (2009) "os alvéolos são hexagonais formando entre as suas arestas um ângulo de 60 . Na construção natural de favos, os alvéolos podem ter uma posição vertical, horizontal, inclinada ou em roseta" (BARROS et al. 2009).

O processo de alveolação da cera é obtido por meio da passagem de lâminas lisas de cera em cilindros ou prensas com as matrizes dos alvéolos, onde a estampa dos alvéolos se imprime em relevo nas folhas lisas de cera recém-fabricadas (Couto e Couto, 1996).

Segundo Costa e Oliveira (2005) a produção de cera alveolada segue alguns passos básicos:

1) Os blocos de ceras (cera bruta) são fundidos no derretedor, onde a temperatura de fusão é mantida constante.

2) Um molde é mergulhado na cera líquida, até que esteja coberto com uma camada de dois milímetros de cera.

3) A cera depositada sobre a madeira é, então, resfriada.

4) Com a cera fria e solidificada, as bordas são cortadas, resultando na produção de duas placas de cera lisa.

5) Essas placas são colocadas para secar.

6) As placas de cera lisa, depois de resfriadas, podem ser imediatamente alveoladas.

7) Os dois cilindros do alveolador devem ser lubrificados para evitar que a cera grude, durante o processo.

8) As placas de cera lisa vão sendo passadas pelo alveolador uma a uma, de maneira que ganhe, em sua superfície, um relevo alveolado, dos dois lados, numa só operação.

9) As placas, então, podem ser armazenadas em local fresco, com boa circulação de ar.

Resumidamente para transformar a cera bruta em cera alveolada são utilizados quatro processos:

- Derretimento: onde a cera é derretida, propicia a retirada de impurezas e purificação.

- Laminação: onde são produzidas as laminas de cera lisa.

- Alveolação: modelagem ou estampagem dos alvéolos na lamina de cera.

- Corte: após a lamina de cera estar alveolada é necessário cortá-la para facilitar o armazenamento.

\subsection{Memorial de Cálculo}

Para realizar os cálculos no decorrer do trabalho é necessário ter o conhecimento de algumas fórmulas, como a de calorimetria e de força de corte. Existem formulas básicas que não são apresentadas na revisão de literatura.

Segundo Halliday et al. (1996) o calor é uma das muitas formas em que a energia expressa na natureza, mas não é uma propriedade de um corpo. É uma energia que flui entre um sistema e 
sua vizinhança devida a uma diferença de temperatura entre elas. A quantidade de calor absorvido ou cedido é calculado pela Equação 1.

$$
Q=m \times c \times \Delta t
$$

O cálculo apresenta a dificuldade para uma substância variar sua temperatura devido a troca de calor. Nesse trabalho esse cálculo é usado para encontrar a vazão de água necessária para refrigerar o sistema de laminação da cera.

Entende-se a força de corte como uma pressão aplicada sobre uma área e vai ser utilizada para calcular o quanto de força é necessária para laminar a cera (Figura 2). A Força de corte e a seção de usinagem podem ser calculadas com as Equações 2, 3 e 4, conforme o Portal Metalica (2014).

$$
\begin{aligned}
& F c=K c \times A \\
& A=b \times h \\
& F c=K c \times b \times h
\end{aligned}
$$

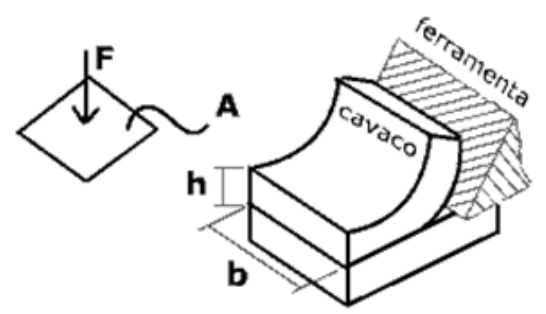

Figura 2: Força de corte sobre uma área. Fonte: Portal Metalica (2014).

\section{APRESENTAÇÃO E ANÁLISE DOS RESULTADOS}

Nesta sessão serão apresentadas as características necessárias para construir um equipamento capaz de alveolar cera. Esse equipamento deve ser capaz de produzir mais de

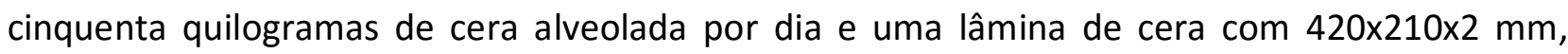
dimensões devido ao padrão de colméia do tipo americana.

\subsection{Sistema de derretimento da cera}

O sistema de derretimento de cera é composto por um tanque em aço galvanizado acoplado a um sistema de aquecimento por gás liquefeito de petróleo (GLP). O tanque tem capacidade para armazenar e derreter 35 quilogramas de cera, chegando a uma temperatura de $65^{\circ} \mathrm{C}$. Para suportar 35 quilogramas de cera o volume interno do tanque deverá ser de $40.000 \mathrm{~cm}^{3}$ (40 litros), levando em consideração uma densidade da cera de $0,960 \mathrm{~g} / \mathrm{cm}^{3}$ e um espaço para segurança. A chapa é de aço galvanizado, para ajudar a evitar a corrosão, como não existe norma que indique qual deve ser o tipo de aço a ser utilizado, foi optado por aço galvanizado. Devido ao custo mais acessível das chapas galvanizadas não vai ser utilizada chapas de aço inox. 


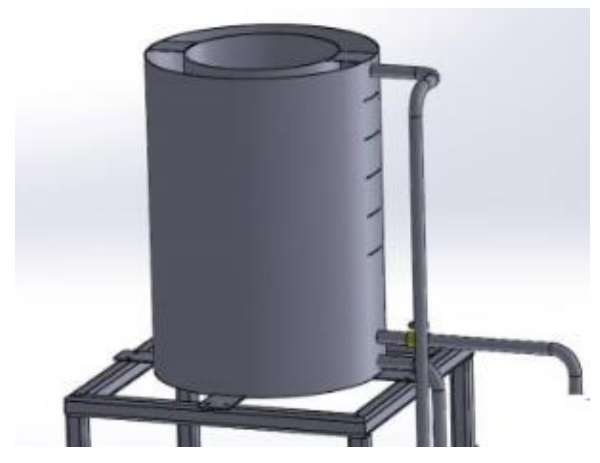

Figura 3: Tanque para derreter a cera.

3.2 Sistema de laminação da cera

\subsubsection{Cilindro}

A temperatura da água no interior do cilindro é de $18^{\circ} \mathrm{C}$, para que a cera se solidifique quando entrar em contato com o cilindro. O volume de água dentro do cilindro é $11.968 \mathrm{~cm}^{3}$ $(11,968$ L). Foi realizado um teste prático com um protótipo, conforme Figura 4 , ao qual foram alternadas entre rotações de 0,5 rpm; $1 \mathrm{rpm}, 1,5 \mathrm{rpm}$ e $2 \mathrm{rpm}$, a rotação que melhor apresentou tempo suficiente para solidificar uma camada de cera que está em contato com sua superfície externa foi a de $1 \mathrm{rpm}$.

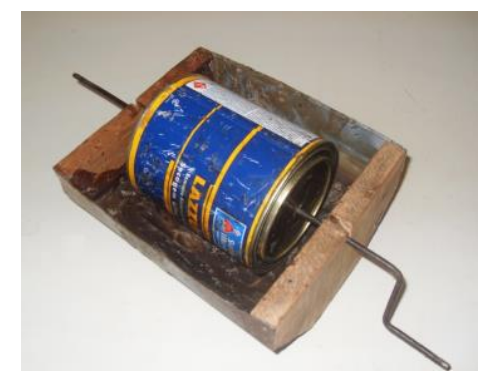

Figura 4: Protótipo para produção de cera alveolada

Inicialmente foi colocado aproximadamente um quilograma de cera bruta para derreter em uma panela. Enquanto espera-se o derretimento da cera, dentro da lata foi adicionado água a temperatura ambiente e cubos de gelo, ficando a uma temperatura de $18^{\circ} \mathrm{C}$. Quando a cera estava liquida, a temperatura de $65^{\circ} \mathrm{C}$, ela foi despejada dentro do reservatório. Como a lata de tinta estava a uma temperatura exterior a $18^{\circ} \mathrm{C}$, a cera em contato com ela se resfriava e solidificava, aderindo-se na lata.

A lâmina pronta tem uma espessura de $2 \mathrm{~mm}$, porém no momento da laminação essa espessura deve ser um pouco maior, ou seja, de $3 \mathrm{~mm}$. Conhecendo a espessura e a rotação no momento da laminação é possível determinar o volume de cera laminada por minuto.

O perímetro do cilindro $\left(6,28^{*}\right.$ r), é 78,5 cm, logo a área lateral do cilindro ( $\operatorname{Pr}^{*}$ b) será 2041 $\mathrm{cm}^{2}$, e o volume de cera laminada $\left(A^{*} h\right)$ é $612,3 \mathrm{~cm}^{3}$, conforme parâmetros da Tabela 1.

Aplica-se nos casos em que o trabalho segue uma linha de desenvolvimento de assuntos contínuos, conforme a estrutura dada abaixo: 
Tabela 1: Parâmetros para o cálculo do volume de cera laminada (Vcl)

\begin{tabular}{ll}
\hline Incógnitas & Valor \\
\hline $\mathrm{Pr}$ & $78,5 \mathrm{~cm}(0,785 \mathrm{~m})$ \\
$\mathrm{r}$ & $12,5 \mathrm{~cm}(0,125 \mathrm{~m})$ \\
$\mathrm{A}$ (do cilindro) & $2041 \mathrm{~cm}^{2}\left(0,20 \mathrm{~m}^{2}\right)$ \\
$\mathrm{b}$ & $26 \mathrm{~cm}(0,26 \mathrm{~m})$ \\
$\mathrm{Vcl}$ & $612,3 \mathrm{~cm}^{3}\left(0,000612 \mathrm{~m}^{3}\right)$ \\
$\mathrm{h}$ (cera laminada) & $0,3 \mathrm{~cm}(0,003 \mathrm{~m})$ \\
\hline
\end{tabular}

A rotação do cilindro é de $1 \mathrm{rpm}$ e o cálculo realizado encontra o volume de $612,3 \mathrm{~cm}^{3}$ para essa rotação.

Para manter o resfriamento é desenvolvido um sistema para trocar continuamente a água no interior do cilindro. Um reservatório de água abaixo do reservatório de cera derretida manterá a água em uma temperatura de $16^{\circ} \mathrm{C}$ utilizando alguns cubos de gelo. A figura 5 apresenta 0 conjunto cilindro e o sistema de refrigeração.

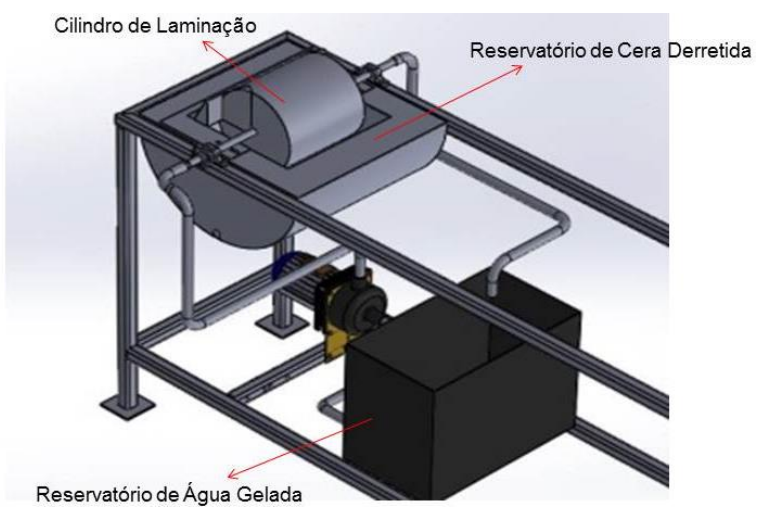

Figura 5: Conjunto cilindro e sistema de refrigeração.

\subsubsection{Reservatório de cera derretida}

Para ocorrer a laminação da cera é necessário que a cera derretida se solidifique junto ao cilindro, a cera derretida deve estar depositada em algum recipiente, um reservatório. 0 reservatório de cera derretida deve ser um pouco maior que o cilindro, e aberto, pois a cera que será depositada neste componente é a cera que vem do derretedor. Além disso, esse reservatório deverá ser capaz de garantir que a cera permaneça líquida, para isso também será utilizado um sistema de Banho Maria, a água estará em contato com a água do derretedor por meio de dois tubos, assim irá se aquecer juntamente com a do mecanismo de derretimento. Para manter a transição do calor entre o derretedor e o reservatório é utilizada uma bomba de água, assim a água quente proveniente do sistema de derretimento é transferida para o reservatório, e posterior a isso retorna para o derretedor para aquecer novamente. A bomba utilizada nesse sistema é uma BAR-400 da Schneider, com capacidade para $3 \mathrm{~m}^{3} / \mathrm{h}$ de vazão. Esse reservatório necessita ser fechado na parte de cima do Banho Maria em virtude de que a água estará em um nível mais baixo do que o do derretedor, caso contrário a água quente transbordará o reservatório. A figura 6 apresenta o reservatório de cera derretida. 


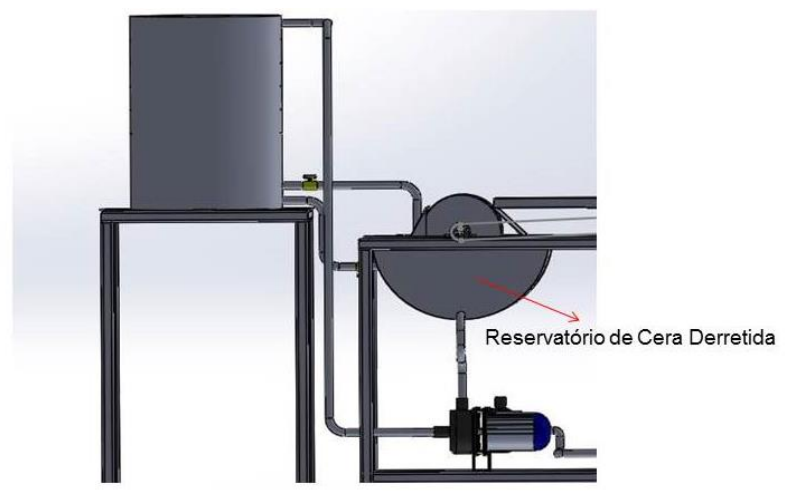

Figura 6: Reservatório de cera derretida.

\subsubsection{Refrigeração da água}

Para refrigerar a água que entra no cilindro é necessário um reservatório. A água nesse reservatório está a uma temperatura próxima a $16^{\circ} \mathrm{C}$, essa temperatura é atingida com adição de cubos de gelo no reservatório, tornando assim um custo de operação mais baixo. Caso a temperatura desça mais que $16^{\circ} \mathrm{C}$ não implicará no funcionamento, pois continuará solidificando a cera quando ela entrar em contato com o cilindro.

A água é trocada dentro do cilindro continuamente, resfriando o sistema. Para ocorrer esse processo é necessária uma bomba para succionar a água do reservatório até o cilindro. Do outro lado a água sairá devido a pressão dentro do cilindro criada pela entrada de mais água, e descerá até o reservatório. É necessária uma tubulação para conduzir a água do reservatório até o cilindro e do cilindro até o reservatório, essa tubulação será plástica, pois a pressão e vazão são baixas e o custo é menor. $O$ diâmetro é compatível com a vazão da bomba e o tubo de metal fixo ao cilindro.

Para escolher a bomba mais adequada é necessário conhecer a vazão de água no sistema. Os dados iniciais para calcular a vazão de água necessária para resfriar a cera no entorno do cilindro, encontram-se na Tabela 2.

Tabela 2: Variáveis para determinar vazão de água necessária para resfriar a cera no entorno do cilindro

\begin{tabular}{lc}
\hline Incógnitas & Valor \\
\hline$\Delta \mathrm{t}$ (inicial da cera) & $65^{\circ} \mathrm{C}$ \\
$\Delta \mathrm{T}$ (final da cera) & $52^{\circ} \mathrm{C}$ \\
$\Delta \mathrm{T}$ (inicial da água) & $16^{\circ} \mathrm{C}$ \\
$\Delta \mathrm{T}$ (final da água) & $18^{\circ} \mathrm{C}$ \\
$\mathrm{C}$ (cera de abelha) & $0,70 \mathrm{kcal} / \mathrm{kg} \cdot{ }^{\circ} \mathrm{C}$ \\
$\mathrm{V}$ (cera de abelha) & $612,3 \mathrm{~cm}^{3}$ \\
$\rho$ (cera de abelha) & $0,972 \mathrm{~g} / \mathrm{cm}^{3}$ \\
$\mathrm{M}$ (cera de abelha) & $595,15 \mathrm{~g} / \mathrm{min}$ \\
$\mathrm{M}$ (água) & $2,707 \mathrm{~kg} / \mathrm{min}$ \\
\hline
\end{tabular}

O volume de cera, $612,3 \mathrm{~cm}^{3}$, é a quantidade de cera que irá se aderir em uma volta completa do cilindro, ou seja, 1 minuto. Multiplicando o volume de cera pela massa específica da cera de abelha, temos uma vazão mássica de 595,15 g/min de cera, conforme a Tabela 2.

Para determinar a quantidade de água necessária para resfriar $612,3 \mathrm{~cm}^{3}$ de cera por minuto podemos utilizar a Equação 1 . Sabendo que o calor perdido da cera será transmitido para 
a água pode-se igualar a quantidade de calor da cera e da água, então resultando em uma vazão mássica de água de $2,707 \mathrm{~kg} / \mathrm{min}(102,46 \mathrm{~L} / \mathrm{h})$.

É necessária uma vazão de $2,707 \mathrm{~kg} / \mathrm{min}\left(0,16246 \mathrm{~m}^{3} / \mathrm{h}\right)$ para manter o cilindro a $18{ }^{\circ} \mathrm{C}$, levando em consideração que a perda carga é baixa, pois a bomba está próxima do reservatório e do cilindro laminador. O conjunto bomba/motor utilizado é o BAR-400, pois vai conseguir suprir as necessidades hidráulicas, conforme dados fornecidos pelo fornecedor Schneider (2014). A Figura 7 representa o conjunto bomba/motor BAR 400. O reservatório de água onde fica a água succionada pela bomba possui capacidade para armazenar 60 litros $\left(0,06 \mathrm{~m}^{3}\right)$ de água.

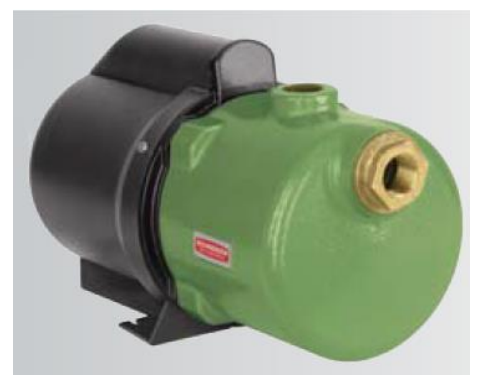

Figura 7: Bomba BAR-400. Fonte: Schneider (2014).

\subsubsection{Laminação da cera}

Para laminar a cera é necessário fazer uso de um mecanismo capaz de cortar a cera enquanto o cilindro estiver girando. A cera estará solidificada junto ao cilindro e a cada movimento de rotação desse cilindro mais cera ficará solidificada junto a ele. É necessário um perfil que se mantenha sempre na mesma posição, para produzir uma lâmina de cera uniforme. Devido a isso ele ficará fixado na estrutura de sustentação. Para regular a espessura da lâmina de cera se faz necessário um mecanismo de ajuste de altura. Para proporcionar uma cera uniforme ainda é necessário usar mais um mecanismo, antes de cortá-la em lâminas, para a parte de cima da cera, além de um controlador de largura (Figura 8).

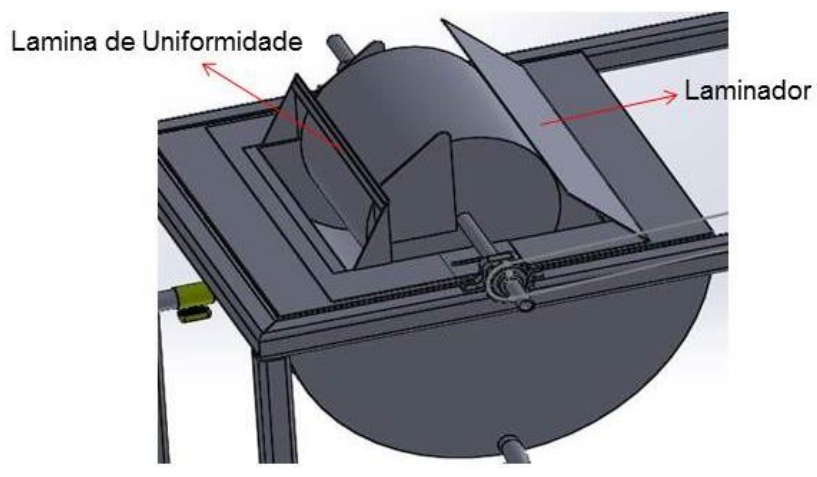

Figura 8: Sistema para uniformizar a cera.

\subsection{Sistema de modelagem da cera}

Não existe uma norma especifica que define os parâmetros de como deve ser a cera alveolada, apenas um padrão de colmeia, a cera alveolada que o equipamento irá produzir terá como base a colmeia americana. 
Após a cera ser laminada ela deve passar por um par de cilindros que irá moldar a cera em formas de alvéolos. O equipamento possui $280 \mathrm{~mm}$ de comprimento dos cilindros e diâmetro de $35 \mathrm{~mm}$. (Figura 9).

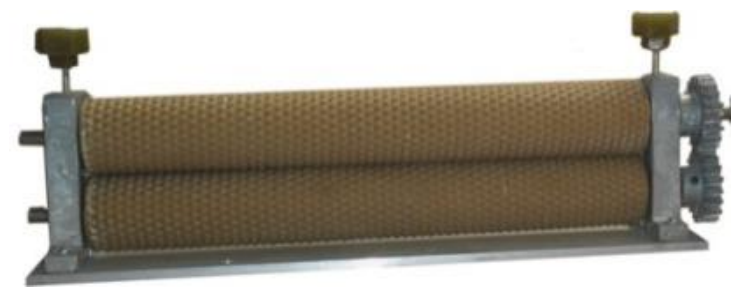

Figura 9: Sistema para moldar a cera. Fonte: Imesul Metal Apícola Ltda (2014)

O equipamento é fixado na estrutura de sustentação e é tracionado por um motor elétrico na mesma rotação que o cilindro laminador. Para a cera não grudar no cilindro alveolador é necessário lubrificá-la, neste caso será utilizado um sistema de lubrificação com água e mel. Esses dois rolos que irão lubrificar a cera são de espuma, a espuma absorve o líquido e quando em contato com a cera passa o líquido para ela. São necessários dois reservatórios para a água e mel, um fica acima e outro abaixo dos rolos. A figura 10 apresenta o sistema para lubrificar a cera.

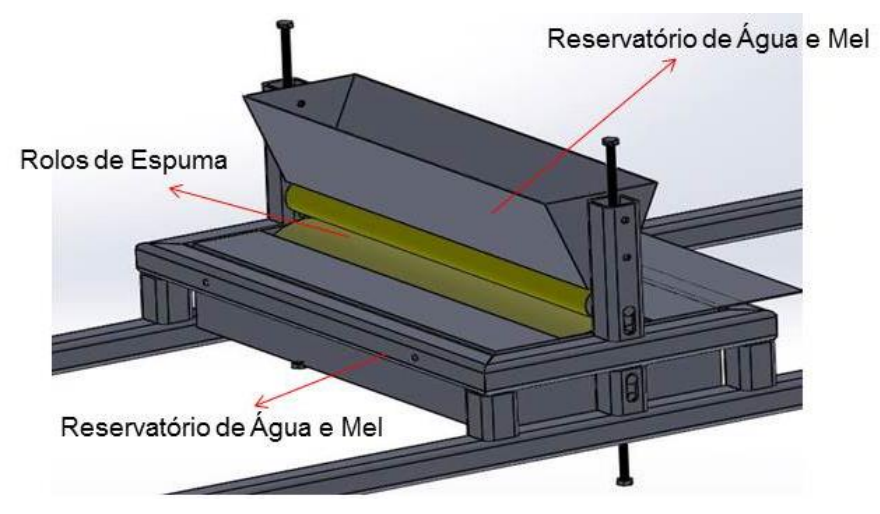

Figura 10: Sistema para lubrificar a cera.

\subsection{Sistema de corte da cera}

Antes de cortar a cera em laminas de 420 mm de comprimento, é necessário deixá-la com $210 \mathrm{~mm}$ de largura. O mecanismo usado para realizar essa tarefa é um cilindro de aço acoplado abaixo de duas laminas circulares. A figura 11 apresenta o sistema para cortar a cera na largura.

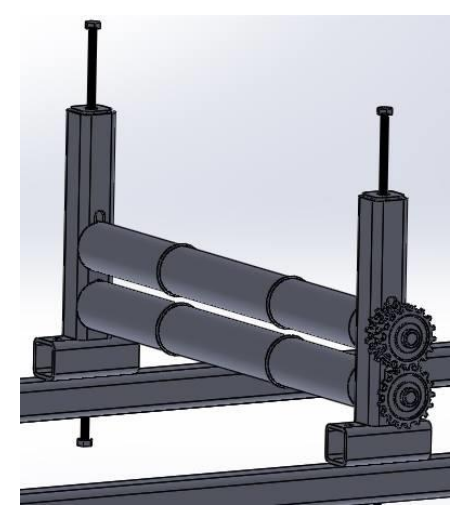

Figura 11: Sistema para cortar a cera na largura. 
A cera passa entre o cilindro e as laminas, devido as laminas estar afiadas e encostadas ao cilindro ocorre o corte da cera, deixando-a com $210 \mathrm{~mm}$ de largura. O sistema é adaptado em uma engrenagem girando na mesma rotação dos demais componentes, 1 rpm.

Para o corte da lâmina de cera alveolada, $420 \mathrm{~mm}$ de comprimento, é necessário que o sistema também possa ser adaptado à engrenagem de rotação. Uma lamina gira na rotação determinada para cortar a lâmina de cera no tamanho desejado e no momento certo ela corta a cera prensando-a contra um cilindro que também está girando.

A rotação para essa lamina é a mesma do resto do sistema, $1 \mathrm{rpm}$. O perímetro que essa lamina forma quando em rotação é o comprimento da cera alveolada, $420 \mathrm{~mm}$. Para poder realizar o trabalho eficientemente nessa rotação, ela deverá girar em um raio de 66,84 mm.

$$
\begin{aligned}
\text { Perímetro } & =2 * \pi * r=420 \mathrm{~mm} \\
r & =66,84 \mathrm{~mm}
\end{aligned}
$$

O cilindro inferior necessita ser de metal, em virtude de que a lamina que corta a cera também ser de aço e com o tempo pode ocorrer ranhuras se for de outro material. A figura 12 apresenta o sistema para cortar a cera no comprimento.

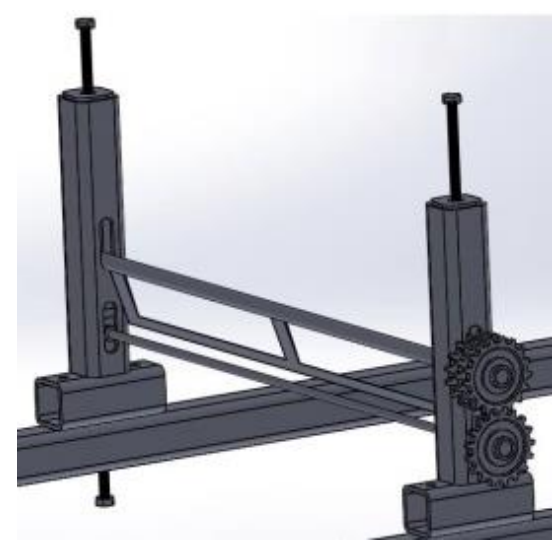

Figura 12: Sistema para cortar a cera no comprimento.

\subsection{Movimentação dos mecanismos}

\subsubsection{Motor elétrico e redutor}

Os sistemas que necessitam rotação, o Cilindro de laminação, Sistema de modelagem da cera, Sistema de corte da cera na largura e o Sistema de corte da cera no comprimento, são acionados por um motor elétrico.

Para descobrir a potência necessária que o equipamento irá requerer primeiramente é preciso descobrir a força de corte para laminar a cera no cilindro, com a Equação 4, resultando em $410,826 \mathrm{~N}$. Seguidamente calcula-se o momento torsor, multiplicando a força de corte (Fc) pelo raio do cilindro, que é $0,125 \mathrm{~m}$, resultando em 51,35 N.m.

A potência do motor elétrico é calculada multiplicando o momento torsor (Mt) pela velocidade angular (W), logo a potência será de 5,375 W (Tabela 3). A velocidade angular é $2 . \pi / 60 \mathrm{~s}$, ou 0,10467 rads/s. 
Tabela 3: Variáveis para determinar a potência necessária para laminar a cera

\begin{tabular}{cc}
\hline Incógnitas & Valor \\
\hline $\mathrm{b}$ & $260 \mathrm{~mm}(0,26 \mathrm{~m})$ \\
$\mathrm{h}$ & $3 \mathrm{~mm}(0,003 \mathrm{~m})$ \\
$\mathrm{Kc}$ & $526,7 \mathrm{kPa}\left(0,5267 \mathrm{~N} / \mathrm{mm}^{2}\right)$ \\
$\mathrm{Fc}$ & $410,826 \mathrm{~N}$ \\
$\mathrm{r}$ & $125 \mathrm{~mm}(0,125 \mathrm{~m})$ \\
$\mathrm{Mt}$ & $51,35 \mathrm{~N} . \mathrm{m}(5,23 \mathrm{kgf} . \mathrm{m})$ \\
$\mathrm{W}$ & $0,10467 \mathrm{rads} / \mathrm{s}$ \\
$\mathrm{P}$ & $5,37 \mathrm{~W}$ \\
\hline
\end{tabular}

A potência necessária para laminar a cera é $5,375 \mathrm{~W}$. No sistema de laminação tem quatro lâminas de corte, uma para deixar a cera uniforme e outra para laminar a cera que será moldada, além de duas laminas menores que cortam a cera nas extremidades do cilindro. Levando em consideração as quatro lâminas de corte, a potência necessária não é superior a $25 \mathrm{~W}$. Devido aos demais sistemas do equipamento não exercerem grandes esforços e uma rotação relativamente baixa ( $1 \mathrm{rpm}$ ) não há necessidade de calcular todos eles, um motor com potência de $100 \mathrm{~W}$ suporta todos os esforços de rotação do equipamento. Levando em consideração uma margem de segurança, uma sobra de potência, o motor utilizado no equipamento é um Motor Monofásico IP55 do tipo Uso Rural da fabricante WEG (2014), semelhante à figura 12 . O motor possui 4 Pólos, Frequência de $60 \mathrm{~Hz}$, Potência de 1/2 cv (0,37 kW) e rpm de 1750 .

Equipamento funciona a uma rotação de um rpm, para reduzir de 1750 para um são utilizados dois redutores de rotação em sequência. Os dois redutores utilizados são do modelo GS 41, com fator de redução 40 do Catálogo GS - Geremia Redutores (2014). Na primeira redução o redutor transforma $1750 \mathrm{rpm}$ em 43,75 rpm. No segundo redutor, ele converte 43,75 rpm inicial a $1,093 \mathrm{rpm}$ final.

\subsubsection{Engrenagens e correntes}

Todos os sistemas do equipamento estão ligados um ao outro por meio de correntes e engrenagens. A Figura 13 apresenta o sistema de rotação dos mecanismos.

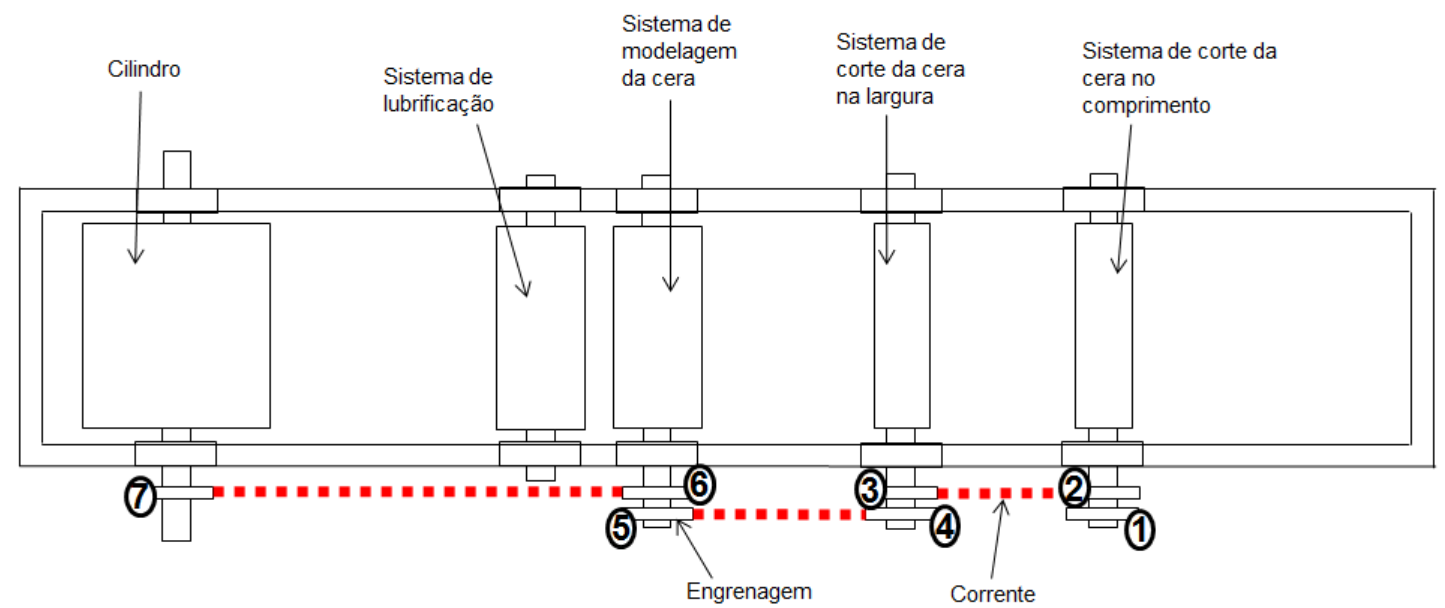

Figura 13: Sistema de rotação dos mecanismos. 
A engrenagem que se encaixa nas características do projeto é a CERELLO ANSI 50 modelo 10A-1/17 Simples, essa engrenagem possui 17 dentes, diâmetro externo de $94 \mathrm{~mm}$. Essa engrenagem é utilizada do número 1 até a 7, na figura 12, devido a mesma rotação entre os sistemas que compõem essas engrenagens, é necessário que estas possuam engrenagens iguais. A engrenagem de número 1 recebe a rotação do redutor e é necessário que esta mantenha a rotação de $1 \mathrm{rpm}$, então a engrenagem na saída do redutor também é a ANSI 50. A corrente que se adapta nas características do projeto e da engrenagem utilizada é a CERELLO ANSI e ISO 50-1, onde essa corrente possui passo de 15,88 mm; diâmetro do rolo de 10,16 mm; largura de 20,3 mm; e carga de ruptura de $2800 \mathrm{~kg}$.

\subsection{Equipamento completo}

O equipamento completo possui a capacidade de transformar a cera bruta em cera alveolada, (Figura 14). Inicialmente deve-se colocar a cera manualmente no derretedor, o qual derrete a cera, depois a cera passa para o estágio onde um cilindro a solidifica em suas paredes externas, e após esse procedimento a cera passa por um processo de corte que da a ela um formato de lâmina, essas lâminas são lubrificadas e passam pelos cilindros de moldagem, moldando os alvéolos. Após ser moldada a lâmina de cera passa pelo sistema de corte de largura deixando em uma largura uniforme. Por último ela é cortada no comprimento desejado e está pronta para ser embalada.

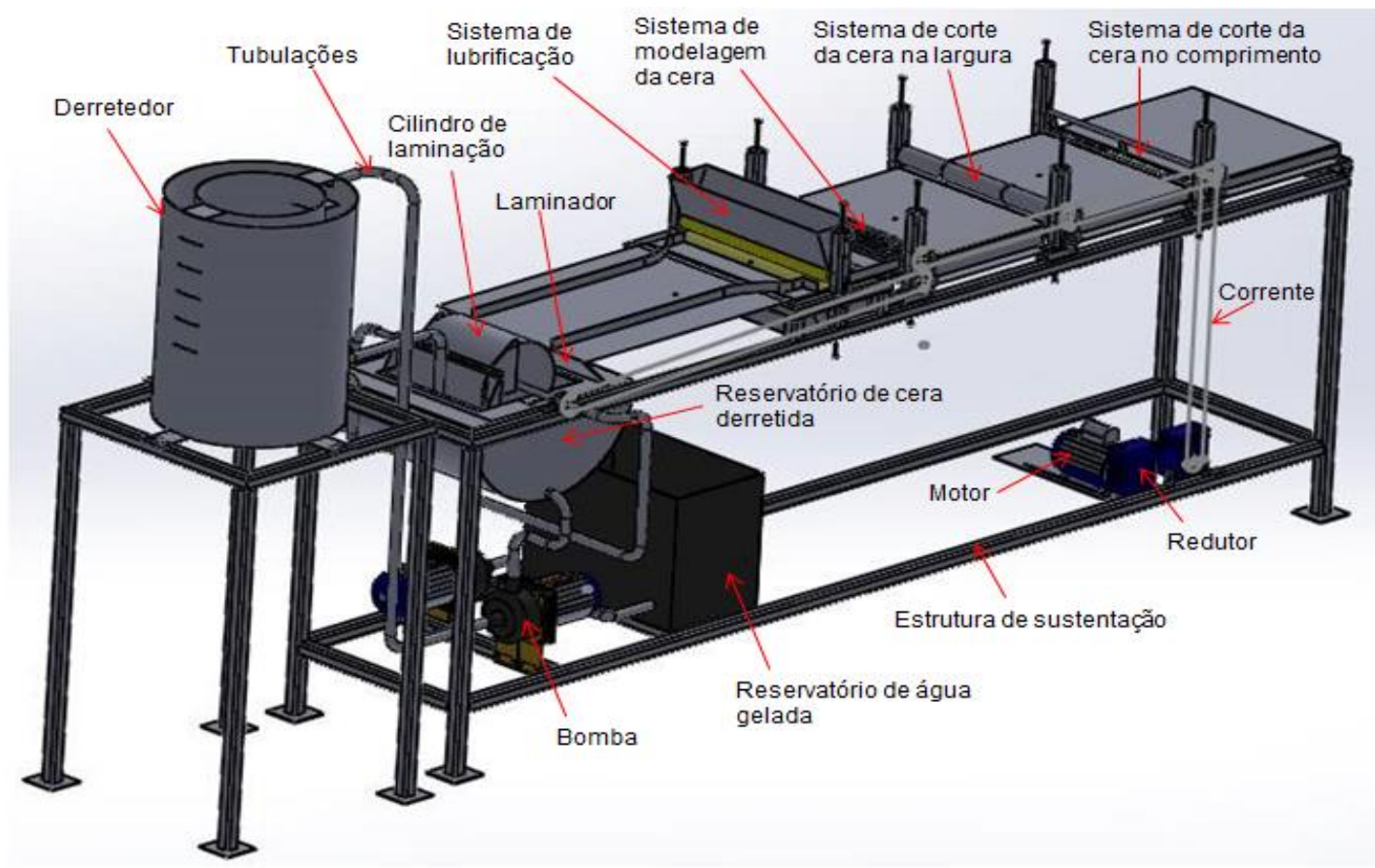

Figura 14: Equipamento completo

Para controlar a temperatura no sistema de derretimento e reservatório de cera derretida é utilizado um termômetro acoplado ao derretedor, o controle para aumentar ou diminuir a temperatura é ajustado com a intensidade da chama proveniente do GLP, bem como, o controle da temperatura no reservatório de água fria é realizado com um termômetro acoplado ao reservatório. 


\section{CONCLUSÕES}

As abelhas tem o papel fundamental na produção de cera, e consomem até sete quilogramas de mel para produzir um quilograma de cera, sendo assim o desenvolvimento desse equipamento iria reduzir esse trabalho por parte das abelhas, permitindo uma maior produção de mel na colmeia.

Foi de grande importância e valor o desenvolvimento do trabalho, o objetivo principal foi atingido de forma satisfatória, pois foi possível desenvolver um equipamento capaz de transformar cera bruta em cera alveolada, com capacidade de produzir mais de cinquenta quilogramas por dia, mantendo a uniformidade. Caso o equipamento for construído possibilitará a produtores de mel um novo método para a aquisição de cera alveolada.

\section{REFERÊNCIAS}

1. ARAÚJO, N. Ganhe muito dinheiro criando abelhas: a técnica do apiário ao alcance de todos. São Paulo: Nobel, 1983.

2. BARROS, A. I. R. N. A.; NUNES, F. H. F. M.; COSTA, M. M. F. Manual de Boas Práticas na Produção de Cera de Abelha: Princípios Gerais. Portugal: Fnap, 2009.

3. CASAFERREIRA. Propriedades Térmicas dos Sólidos, Líquidos e Gasosos. 2014. Disponível em: <http://www.casaferreira.com.br/aquecimento/resistencias/inform_proprisoli.asp> Acesso em: 28 ago. 2014.

4. CERELLO. Catálogo de Engrenagens e Correntes. 2014. Disponível em: <http://www.cerello.ind.br/index.php> Acesso em: 28 set. 2014.

5. COUTO, R. H. N.; COUTO, L. A. Apicultura: Manejo e Produtos. 1. ed. Jaboticabal - SP - FUNEP: [s.n.], 1996

6. CORRÊA, M. P. F. Produção de Mel. Embrapa. 2003. Disponível em: <http://sistemasdeproducao.cnptia.embrapa.br/FontesHTML/Mel/SPMel/> Acesso em: 13 nov. 2014.

7. COSTA, P. S. C.; OLIVEIRA, J. S. Manual Prático de Criação de Abelhas. Viçosa: Aprenda Fácil, 2005. $424 \mathrm{p}$.

8. GEREMIA REDUTORES, 2014. Disponível em: <http://www.geremiaredutores.com.br/> Acesso em: 16 set. 2014.

9. HALLIDAY, D., RESNICK, R., WALKER, J. Fundamentos de Física 2: Gravitação, Ondas, Termodinâmica. 4. ed. Rio de Janeiro: LTC, 1996.

10. HOSSAIN, M. E.; KETATA, C.; ISLAM, M. R. Proceedings of the Third International Conference on Modeling, Simulation and Applied Optimization, 2009, U.a.e. Experimental Study of Physical and Mechanical Properties of Natural and Synthetic Waxes Using Uniaxial Compressive Strength Test. 2009. 5 p.

11. HUERTAS, A. A. G.; GARAY, L. G.; SÁ, V. G. M. Cera de Abelhas. Viçosa: Universidade Federal de Viçosa, 2009.

12. IMESUL METAL APÍCOLA LTDA. Cilindro Alveolador de Cera. Lages, SC. 2014. Disponível em: <http://www.imesul.com.br/produto.php?id=76> Acesso em: 16 set. 2014. 
13. LOSTLAKEGARDENS. Beekeeping Equipment. 2013. Disponível em: <http://lostlakegar dens.wordpress.com/2013/05/16/beekeeping-equipment/>. Acesso em: 13 nov. 2014.

14. NUNES, L. A.; OLIVEIRA, M. E. C. SILVEIRA, T. A.; MARCHINI, L. C.; SILVA, J. W. P.. Produção de Cera. Universidade de São Paulo. Piracicaba: ESALQ - Divisão de Biblioteca, 2012. (Série Produtor Rural, no 52).

15. PORTAL METALICA. Equacionamento da força de corte. 2014. Disponível em: <http://www.metalica.com.br/equacionamento-da-forca-de-corte> Acesso em: 24 set. 2014.

16. SCHNEIDER. Catálogo de Bombas. 2014. Disponível em: <http://www.schneider.ind.br/cata logo/> Acesso em: 16 set. 2014.

17. WEG. Seleção de Motores Elétricos. 2014. Disponível em: <http://ecatalog.weg.net/TEC_ CAT/tech_motor_dat_web.asp> Acesso em: 16 set. 2014. 